\title{
Terapia Celular: Novos Conceitos - Novas Perspectivas
}

\author{
Emerson C. Perin ${ }^{1}$, Marlos R. Fernandes ${ }^{1}$, Guilherme V. Silva ${ }^{1}$
}

E m edição anterior da Revista Brasileira de Cardiologia Invasiva ${ }^{1}$, discutimos a mudança de paradigma decorrente da demonstração da presença de divisão celular de cardiomiócitos adultos em corações transplantados. As implicações dos achados descritos por Quaini et al. ${ }^{2}$ são dramáticas, pois contradizem o conceito básico de ausência de atividade mitótica em órgãos terminalmente diferenciados, como o coração e o sistema nervoso central. Conseqüentemente, observamos uma revolução científica, em que pesquisadores estudam as interações celulares responsáveis pela manutenção da homeostasia em órgãos especializados, como o coração. Nesse contexto, a terapia celular surge com um objetivo ambicioso e sem precedentes: reparar o coração após estabelecida a lesão miocárdica. Neste editorial, daremos continuidade à série de artigos de revisão publicada anteriormente, que avaliou a terapia celular no infarto agudo do miocárdio ${ }^{3}$, na cardiomiopatia isquêmica ${ }^{4}$ e na cardiomiopatia dilatada $^{5}$. Entretanto, ao invés de resultados de estudos clínicos e pré-clínicos, discutiremos os conceitos e as direções futuras desse novo capítulo que começa a ser escrito na história do tratamento das doenças cardiovasculares.

Para entendermos e avaliarmos os resultados dos trabalhos clínicos realizados até o presente momento, estudando o papel da terapia celular em Cardiologia, precisamos revisitar alguns conceitos básicos de metodologia. Como qualquer novo tratamento, a terapia celular, antes de ser aceita, deve ter seu perfil de segurança precisamente determinado. Os resultados de trabalhos clínicos de fase I avaliados em conjunto são importantes para definirmos o perfil de segurança em relação a: população de pacientes tratados, contexto clínico, via e dose de administração. Até o presente momento, a maioria dos estudos clínicos demonstrou a segurança do uso de células autólogas (mononucleares derivadas da medula ou progenitoras circulantes) para o tratamento de pacientes com insuficiência cardíaca congestiva ou pós-infarto agudo do miocárdio ${ }^{6}$. As vias intracoronária e intramiocárdica também revelaram perfil de segurança favorável. Apesar de grande variação entre os estudos, doses até $2,5 \times 10^{9}$ não se associaram a efeitos adversos. O passo seguinte para o estabelecimento de uma nova terapia é a demonstração de sua eficácia. Esse é um dos pontos de maior controvérsia no momento. Com resultados muitas vezes divergentes e conclusões precipitadas a partir de trabalhos com pequena amostragem, a terapia celular enfrenta grande ceticismo por parte da comunidade científica. Tentaremos entender o contexto atual para podermos mais precisamente fazer considerações a respeito de perspectivas futuras.

O objetivo final de qualquer forma de tratamento é reduzir a morbidade e a mortalidade de uma doença específica, em uma população definida de pacientes. Para isso, precisamos de ensaios clínicos aleatorizados com grande número de pacientes e acompanhamento prolongado. Por questões práticas, muitas vezes adotamos marcadores substitutos, ou surrogate markers, como uma ferramenta para avaliarmos a eficácia de drogas ou terapias em trabalhos com menor número de pacientes. É o caso do uso de fração de ejeção do ventrículo esquerdo como objetivo primário em estudos que avaliaram o papel da injeção de células mononucleares da medula óssea em pacientes com infarto agudo do miocárdio. Apesar de ser reconhecido como erro estatístico (erro tipo 2), o uso de amostragem insuficiente e sem poder de detectar diferenças entre grupos vem confundindo a análise dos resultados das pesquisas. Resultados de estudos de fase I, os quais envolvem pequeno número de pacientes para a avaliação de segurança, revelaram "ausência de benefício terapêutico", gerando grande incerteza na comunidade médica a respeito da validade da nova terapia. Vale a pena ressaltar que, na história da Cardiologia mundial, diversas novas terapias enfrentaram ceticismo inicial, como foi o caso, por exemplo, do uso de trombolíticos no infarto agudo do miocárdio. Portanto, é preciso enfatizar a importância de analisar trabalhos com metodologia rígida e com amostragem suficiente antes de concluirmos a respeito da validade de uma nova terapia. Dessa maneira, a injeção intracoronária de células mononucleares da medula óssea após infarto agudo do miocár-

\footnotetext{
1 Stem Cell Center, Texas Heart Institute at St. Lukes Episcopal Hospital - Houston, Texas, Estados Unidos.

Correspondência: Emerson C. Perin. Texas Medical Center MC2-255 - PO Box 20345 - Houston, Texas, USA - 77225-0345

E-mail: eperin@bluegate.com

Recebido em: 12/2/2008 • Aceito em: 13/2/2008
} 
dio, conduzida em ensaios clínicos de metodologia adequada, além de segura, foi relacionada a melhora da fração de ejeção, aos quatro meses, e a redução de eventos clínicos, em acompanhamento de um $\mathrm{ano}^{7,8}$.

Além da complexidade inerente ao estudo de novos tratamentos, a terapia celular introduz um novo fator de confusão: a qualidade do produto celular. É sabido que os resultados de tratamentos dependentes do operador, como é o caso dos procedimentos cirúrgicos, devem ser generalizados com muita cautela. Procedimentos realizados por operadores diferentes podem resultar em desfechos clínicos distintos. Quando administramos por via transendocárdica células autólogas em regiões de miocárdio hibernado, estamos introduzindo mais um fator de confusão que se soma à técnica do operador, qual seja a qualidade das células administradas. Resultados preliminares de estudos em andamento, apresentados em congressos científicos, enfatizam a importância da qualidade das células para a obtenção de resultado terapêutico ideal. Isso pode explicar a divergência dos resultados de estudos de metodologias similares, como o ASTAMI e o REPAIRAMI $^{9}$. Portanto, o efeito terapêutico final decorre da interação entre a qualidade das células administradas, a via de administração e a condição clínica do paciente (Figura 1). O uso futuro de células de origem alogênica em trabalhos clínicos contribuirá para a homogeneização do tratamento, assegurando o uso de células de boa qualidade para todos os indivíduos tratados.

A incerteza acerca do mecanismo preciso de ação das células após sua administração e a incapacidade de demonstrar a presença tardia e a incorporação ao tecido miocárdico das células injetadas geraram a hipótese de um efeito parácrino transitório como potencial mecanismo de ação. Resultados de acompanhamento por 18 meses $^{10}$ de pacientes submetidos a infusão intracoronária de células mononucleares da

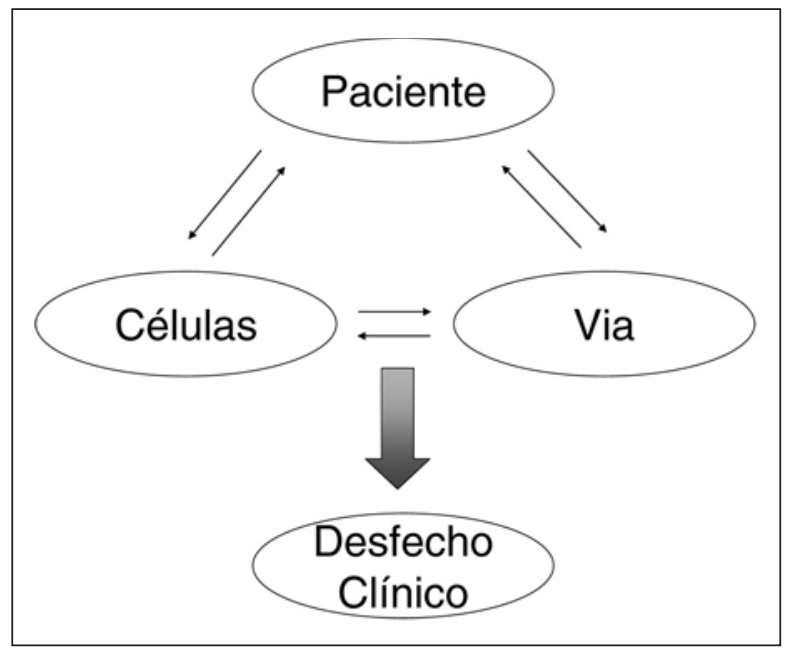

Figura 1 - Interação entre paciente, via de administração e qualidade do produto celular na determinação do desfecho clínico. medula após infarto agudo do miocárdio revelaram efeito terapêutico transitório em relação à recuperação de fração de ejeção. Combinados, esses dados sustentam o questionamento atual a respeito da necessidade de repetição do tratamento para a obtenção de maior eficácia terapêutica.

Percebemos que ainda restam várias questões relacionadas a essa nova terapêutica em potencial. Acumularam-se dados de trabalhos clínicos de fase I que suportam sua segurança e permitem a progressão para estudos clínicos com enfoque na avaliação de eficácia terapêutica. Devemos entender que a análise futura desses estudos representará um grande desafio, e necessitará de um tempo maior até atingirmos conclusões definitivas. Novos fatores de confusão inerentes a essa nova terapia poderão influenciar os desfechos clínicos e levar a maior variabilidade nos resultados finais. Entretanto, lembrando Earl Nightingale: "Não deixemos que o receio do tempo que levamos para fazer algo se entreponha em nosso caminho. O tempo passará de qualquer forma; devemos, portanto, aproveitálo da melhor maneira possível".

\section{REFERÊNCIAS BIBLIOGRÁFICAS}

1. Fernandes MR, Perin EC. Regeneração cardíaca. Coração: um órgão pós-mitótico. Rev Bras Cardiol Invas. 2007;15(1):61-9.

2. Quaini F, Urbanek K, Beltrami AP, Finato N, Beltrami CA, Nadal-Ginard B, et al. Chimerism of the transplanted heart. N Engl J Med. 2002;346(1):5-15.

3. Angeli FS, Oliveira EM. Terapia celular no tratamento do infarto agudo do miocárdio. Rev Bras Cardiol Invas. 2007;15(2): 145-50.

4. Fernandes MR, Silva GV. Terapia celular no tratamento da insuficiência cardíaca isquêmica. Rev Bras Cardiol Invas. 2007;15(3):277-84.

5. Sanz R, Jimenez-Quevedo P. Terapia com células-tronco em cardiomiopatia não-isquêmica. Rev Bras Cardiol Invas. 2007;15(4):416-20.

6. Abdel-Latif A, Bolli R, Tleyjeh IM, Montori VM, Perin EC, Hornung CA, et al. Adult bone marrow-derived cells for cardiac repair: a systematic review and meta-analysis. Arch Intern Med. 2007;167(10):989-97.

7. Schachinger V, Erbs S, Elsasser A, Haberbosch W, Hambrecht $\mathrm{R}$, Hölschermann $\mathrm{H}$, et al. Intracoronary bone marrowderived progenitor cells in acute myocardial infarction. $\mathrm{N}$ Engl J Med. 2006;355(12):1210-21.

8. Schachinger V, Erbs S, Elsasser A, Haberbosch W, Hambrecht $\mathrm{R}$, Hölschermann $\mathrm{H}$, et al. Improved clinical outcome after intracoronary administration of bone-marrow-derived progenitor cells in acute myocardial infarction: final 1-year results of the REPAIR-AMI trial. Eur Heart J. 2006;27(23):2775-83.

9. Seeger FH, Tonn T, Krzossok N, Zeiher AM, Dimmeler S. Cell isolation procedures matter: a comparison of different isolation protocols of bone marrow mononuclear cells used for cell therapy in patients with acute myocardial infarction. Eur Heart J. 2007;28(6):766-72.

10. Meyer GP, Wollert KC, Lotz J, Steffens J, Lippolt P, Fichtner $S$, et al. Intracoronary bone marrow cell transfer after myocardial infarction: eighteen months' follow-up data from the randomized, controlled BOOST (BOne marrOw transfer to enhance ST-elevation infarct regeneration) trial. Circulation. 2006;113(10):1287-94. 